\title{
SOME ANATOMIC FEATURES OF THE CHILD'S THORAX AND THEIR PRACTICAL APPLICATION IN PHYSICAL DIAGNOSIS *
}

\author{
GEORGE FETTEROLF, M.D. AND J. CLAXTON GITTINGS, M.D. \\ PIIILADELPHia
}

Since the study of anatomy by means of frozen sections and the use for the same purpose of bodies with the viscera hardened in situ have come into vogue, many new ideas have been acquired and many misconceptions corrected. While the study of soft preparations in the dissecting and autopsy rooms has been responsible for almost all our knowledge of gross anatomy, it is not until we examine conditions more nearly as they are during life that we get a really true conception of anatomic relations. The mere opening of the thorax and abdomen under ordinary conditions will of itself cause a change in the shape and relations of the various organs, and when conditions are still further disturbed by dissection or by the successive stages of an autopsy it is possible to get only an approximate idea of conditions as they existed during life.

Our work has consisted of making dissections and of cutting sections of the bodies of infants which had been injected with 10 per cent. dilution of liquor formaldehydi and then frozen. The results of our study of these preparations are embodied in the present paper.

Examination of the child's thorax reveals many important facts, the conception of which is generally inexact. One of these facts is that the thymus body is a structure of considerable size and extent, reaching well beyond the borders of the sternum and separating widely the upper lobes of the two lungs (Figs. 1, 3 and 4). Posteriorly, at least in the first few weeks of life, it extends in places to the trachea (Figs. 2 and 6). It would seem that sudden death at this period, due to respiratory failure, might be caused by even moderate increase in the size of the gland. Delay in the normal involution of this body would extend the danger period.

A point which is very noticeable in the hardened gland is that the upper median portion is deeply indented posteriorly (Fig. 5) by the left innominate vein, which lies immediately on the anterior facies of the

* From the Laboratory of Anatomy of the University of Pennsylvania.

* Read before the joint meeting of the Pediatric Section of the New York Academy of Medicine and the Philadelphia Pediatric Society, Philadelphia, Nor. 8, 1910. 
trachea (Fig. 6). When the size and distensibility of this vessel and the softness and small caliber of the trachea are taken into consideration we have a possible mechanical explanation of the sudden deaths which occur in the young during anesthesia. A slight embarrassment of the right heart or any factor, such as struggling, which would cause a rise of venous pressure, would dilate this vein. Braced firmly on its anterior surface by the thymus, the only direction in which it could extend would be posteriorly and in such an event there would be of necessity compression to a greater or less extent of the trachea. If the amount of compression were great, sudden death would be the result. If of a slighter degree the amount of asphyxia caused by it would tend to raise pressure and canse still further dilatation of the innominate vein, and thus a vicious circle would be established which would soon result in death. If there is any truth in this theory, venesection would be indicated in the emergency.

Another noteworthy point is the amount of space eccupied by the heart, which extends at its greatest depth from the sternum to the esophagus, aorta and spinal column (Figs. 7, 8 and 9). In this connection it is evident that a dilated heart or pericardium must exert such marked pressure on the lower third of the upper lobe and the upper two-thirds of the lower lobe of the left lung (Figs. $r$ and 8 ), that in such conditions the frequent presence of bronchial breathing, heard over the back of the chest, is easily accounted for.

It is a well-known fact that in infancy the ribs lie nearly in a horizontal plane and that the sternum occupies a higher position than in the adult, its top lying opposite the body of the first thoracic vertebra. ${ }^{1}$ Later in life the sternum drops to a lower plane, owing probably to increase in the size of the lungs, a relative decrease in size of the liver, an actual decrease in size of the thymus and the assumption by the child of the vertical as opposed to the horizontal position.

The internal anatomy of the heart shows many points of interest.

The right auricle lies directly in front of the right half of the left auricle (Fig. 10) but, with the exception of a portion of the appendix (Fig. 9), does not touch the chest wall. The superior vena cava enters the auricle in a plane anterior to that of the inferior cava (Fig. 11). Blood from the latter is directed upward by the Eustachian valve and not to the left, as is commonly supposed. The foramen ovale lies in an almost horizontal plane (Fig. 11), and not vertically and facing to the left. Dextro- or levo-position of the new-born is, therefore, of no importance in aiding the closure of this opening, a point to be elaborated in a future communication.

The tricuspid orifice, an oval ring, is practically vertical (Fig. 12), not horizontal, and opens to the left and slightly forward. The bottom

1. Piersol, George A.: Human Anatomy, 1907, p. 164. 
of the right ventricle is so nearly on the level of that of the right auricle (Fig. 12) that gravity must play little if any part in the passing of the blood through the tricuspid orifice. The negative pressure caused by the ventricular diastole and the veno-auricular pressure are the principal factors favoring the rapid filling of the ventricle.

The right ventricle constitutes practically all of the heart which touches the anterior chest wall (Figs. 7 and 12) and is slightly overlapped on each side by the right and left lungs (Fig. 7). Posteriorly it is bounded by two structures, the left ventricle below (Figs. 7 and 15) and the root of the aorta above (Fig. 12). Aortic sounds, therefore, at the level of the second costal cartilage must be heard through the medium of the upper part of the right ventricle, that part known as the infundibulum or conus arteriosus (Figs. 8 and 12), from which arises the pulmonary artery.

The pulmonary artery lies to the left of and slightly anterior to the aorta (Fig. 4) and is separated from the anterior chest wall by the lower portion of the thymus body (Fig. 4). It divides into a long right branch and a short left one. The former runs under the aortic arch and continues along the upper border of the left auricle (Figs. 9 and 12). The left branch passes to the root of the lung across and directly in front of the left bronchus (Fig. 4).

The left auricle is a horizontal cylinder flattened from before backward (Figs. 9 and 12), lying at the extreme back of the heart and extending throughout the entire width of the base of the heart (Fig. 10). It is bounded in front by the right auricle and the left ventricle (Fig. 10), behind by the thoracic aorta (Figs. 9 and 10) and esophagus (Fig. 10), and above by the right pulmonary artery and the left bronchus (Figs. 9 and 12). The right end lies directly behind the right auricle (Fig. 10) and consists of the orifices of the two right pulmonary veins (Fig. 9). At the left end are four openings (Fig. 12). Above and posteriorly are those of the two left pulmonary veins, while above and anteriorly is the opening of the auricular appendix, the two being separated by a practically vertical septum. Below and anterior is the fourth opening, the mitral orifice, which lies in a plane approximately parallel to the anterior facies of the vertebral column (Fig. 12) at this level. The mitral and tricuspid orifices, therefore, lie in planes which are almost at right angles to each other (Fig. 12).

The left ventricle is bounded behind by the left auricle (Fig. 7 ), and in front, except for the extreme left hand edge, by the right ventricle (Figs. 7 and 13). The two posterior leaflets of the aortic valve are attached to the base of the anterior mitral leaflet (Fig. 12), a fact which furnishes the most plausible theory to account for the mechanism of a "Flint's murmur." 


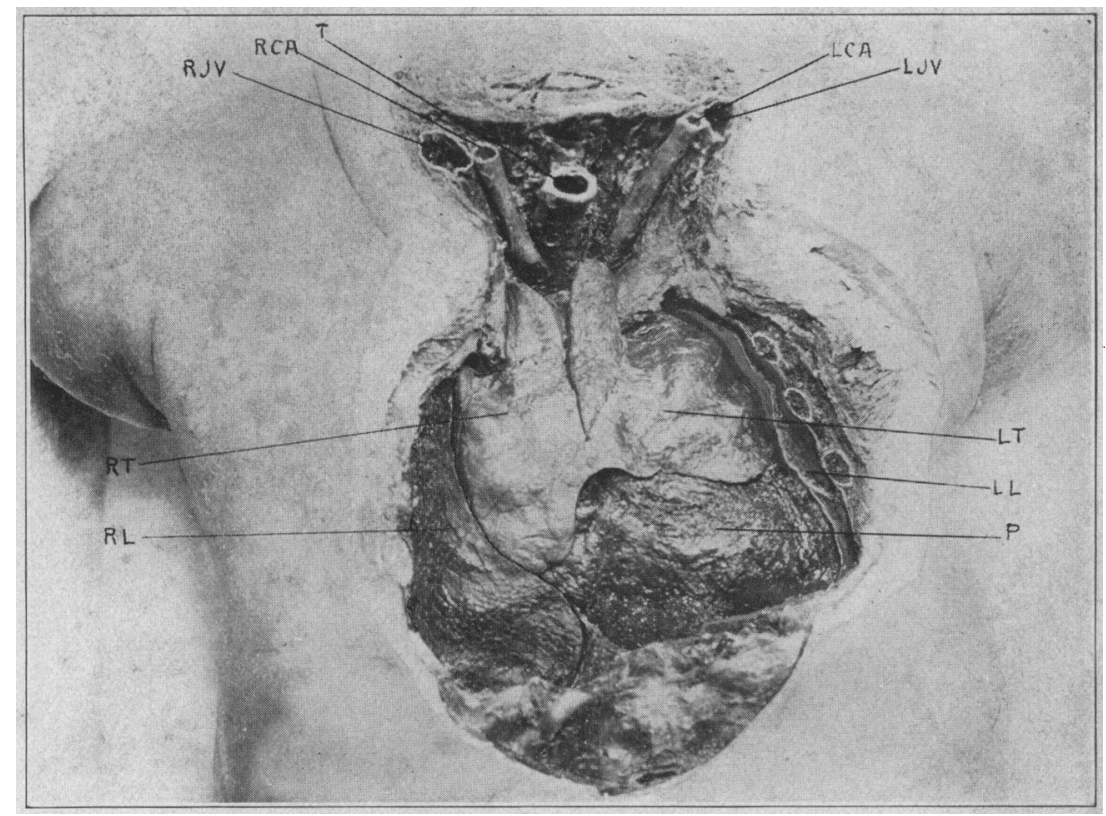

Fig. 1.-Body of a new-born child from which the median portion of the anterior chest wall has been removed. RL, right lung; RT, right lobe of thymus; RJV, right internal jugular vein; RCA, right common carotid artery; T, trachea; LCA, left common carotid artery; LJV, left internal jugular vein; LT, left lobe of thymus; LI, left lung; $P$, perjeardium.

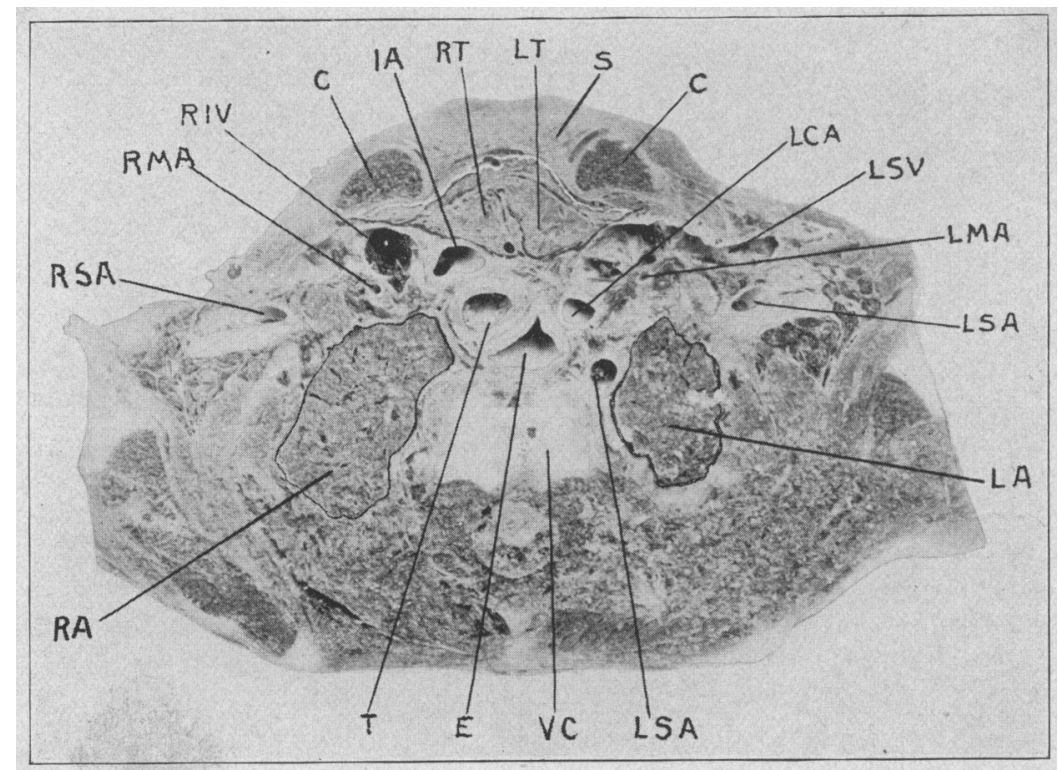

Fig. 2.-Horizontal section, viewed from below, of the body of a new-born child at the level of the upper part of the sterno-clavicular articulation. VC, vertebral column; $\mathrm{E}$, esophagus; ' $\mathrm{T}$, trachea; RA, apex of right lung; RSA, right subclavian artery; RMA, right intermal mammary artery; RIV, right innominate vein; C, C, clavicles; IA, innominate artery; RT, right lobe of thymus; LT, left lobe of thymus; S, sternum; LCA, left common carotid artery; LSV, left subclavian vein; LMA, left internal mammary artery; LSA, LSA, left subclavian artery; LA, apex of left lung. 
The arch of the aorta passes almost directly backward (Figs. 4, 9 and 12), instead of from right to left. When it is recognized that the aorta arises from the heart to the left of the midsternal line and descends in the thorax, but slightly to the left of the middle of the vertebral column, this position of the arch is readily understood. In its course backward and very slightly to the left it separates the lower part of the trachea from the adjacent portion of the left lung (Fig. 3), making a distinct arciform groove in the mediastinal facies of the latter organ.

When the heart is considered in toto it is seen that the only portions which touch the anterior chest wall are a part of the right auricular

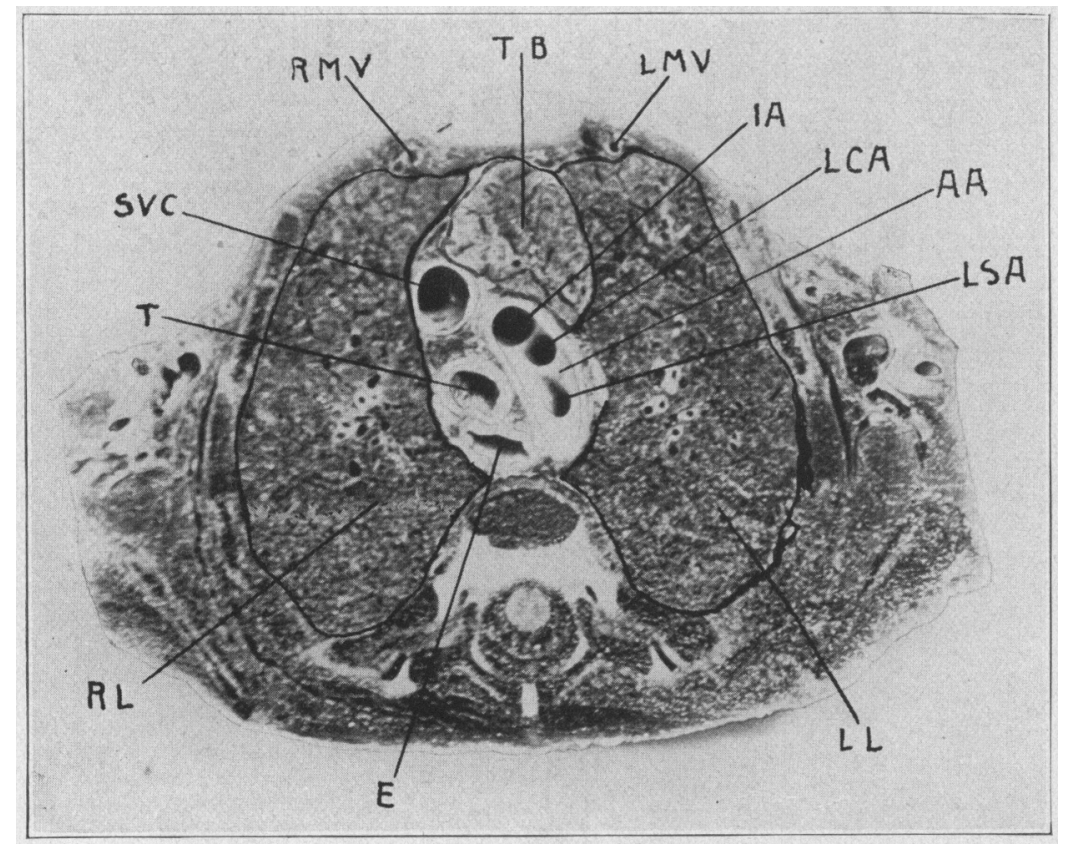

Fig. 3.-Horizontal section, viewed from below, of the body of a new-born child at the level of the upper border of the second rib. Ji, esophagus; RL, right lung; 'T, trachea; SVC, superior vena cava; RMV, right internal mammary vesrels; TB, thymus body; LMV, leit internal mammary vessels; IA, innominate artery; LCA, left common carotid artery: AA. aortic arch: LSA, left subelavian artery; LI, left lung.

appendix and all of the right ventricle, except perluaps the upper part of the infundibulum. The tip of the left ventricle, while it may come into contact with the chest wall, is probably covered by the tip of the lower lobe of the left lung (Fig. 7 ), that part called the lingula.

Examination of the position of the greater azygos rein (Fig. 11) makes clear the fact that pressure on it by a dilated heart is impossible, 


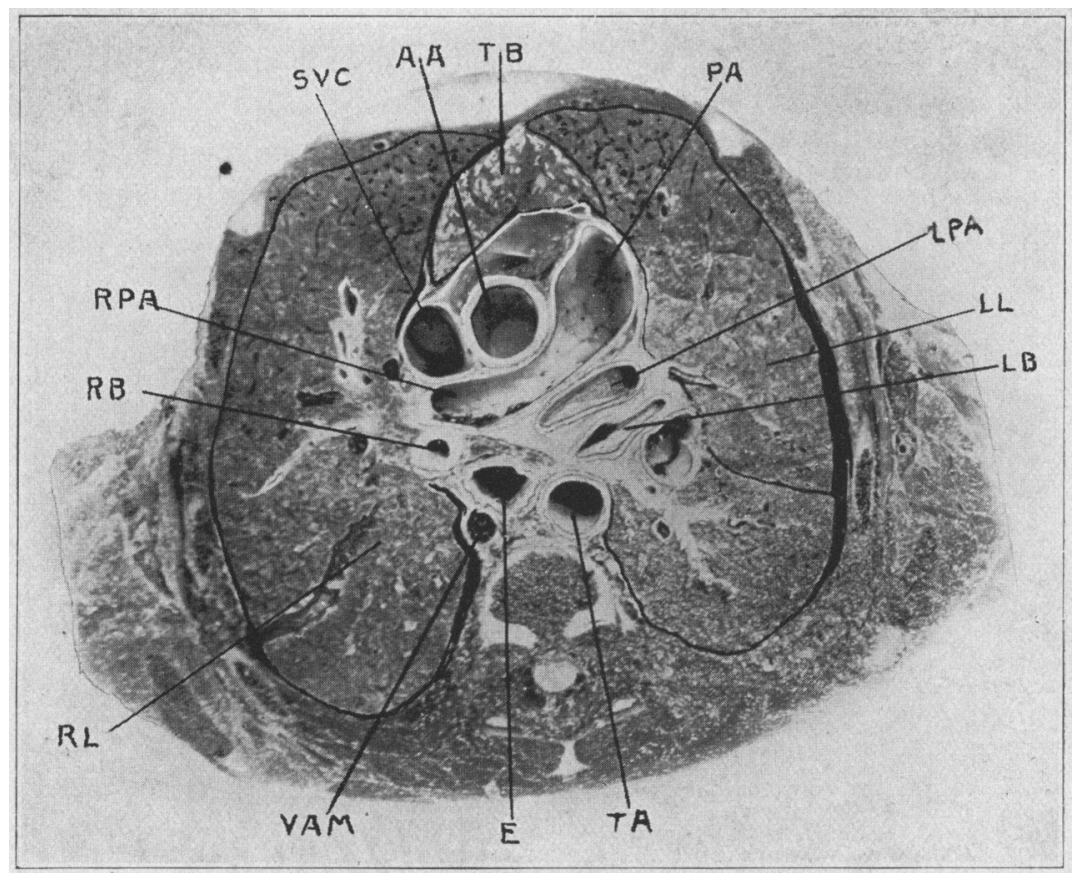

Fig. 4.-Horizontal section, viewed from below, of the body of a new.born child at the level of the upper border of the third rib. E, esophagus; VAM, vena azygos major; RL, right Jung; RB, right bronchus; RPA, right pulmonary artery; SVC, superior rena cava; AA. ascending part of aortic areh; TB, thymus body; PA, pulmonary aorta; LPA, left pulmonary artery; LL, left lung; LB, left bronchus; TA, thoracic aorta.

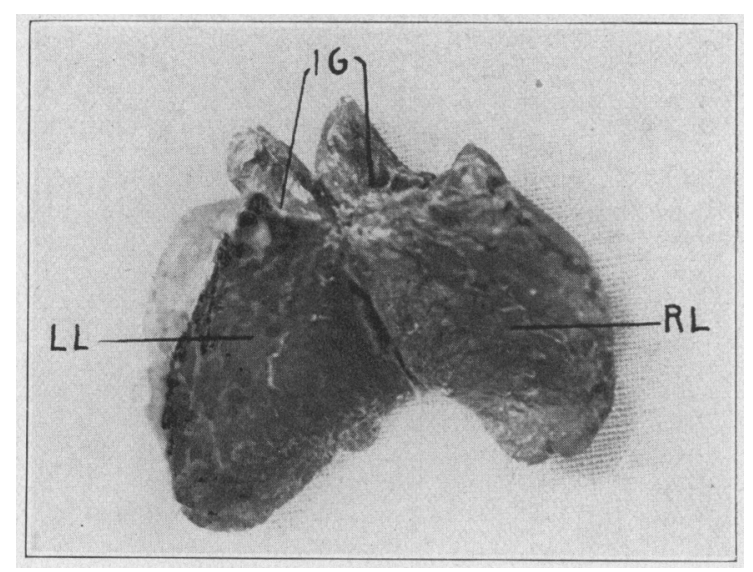

Fig. o.-Posterior view, life size, of the thymus body of the new-born child depicted in Figs. 1 and 6 . LL, left lobe; IG, groove for left innominate vein; $\mathrm{RL}$, right lobe. 
whereas pressure on the pulmonary veins, especially the right, can occur with even moderate degrees of cardiac enlargement (Fig. 17). Partial occlusion of these latter veins would explain in large part both the hydrothorax and the pulmonary congestion which are seen in many cases of enlarged heart without signs of stasis in the systemic circuit.

If, in the case of mitral regurgitation, the problem were simply one of overcoming the leakage by the force necessary to pump through the pulmonary artery the normal amount of venous blood, plus the arterial blood, which is returned from the left auricle, the right ventricle would probably be efficient for a long time. From the beginning of mitral leakage, how-

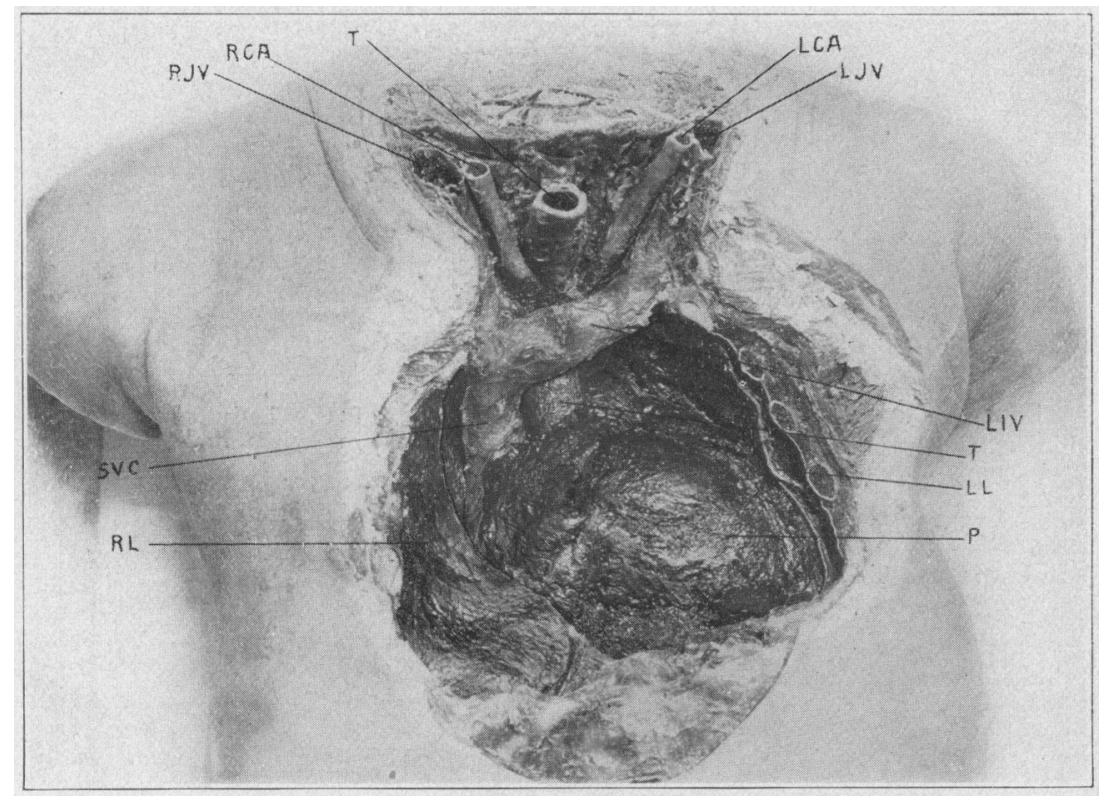

Fig. (6.-Body of the new-born child depicted in Fig. 1, the thymus having been removed. RL, right Jung; SVC, superior vena cava; RJV, right internal jugular vein; RCA, right common carotid artery; I', I', trachea; LCA, left common carotid artery; LJV, left internal jugular vein; LIV, left innominate vein; LL, left lung; $\mathbf{P}$, pericardium.

ever, two changes take place, enlargement of the left auricle and, although not quite as early, a similar change in the left ventricie. The former must include enlargement of the appendix as well as of the main cavity, and the appendix, if at all increased in size, is sure to exert pressure on the upper left pulmonary vein, while enlargement of the ventricle would cause pressure on the lower vein (Fig. 18). Compression of these veins at once favors congestion in the radicles, both arterial and venous, in the lung and pleura, the veins of the human pleura opening as they do into 
the pulmonary veins, ${ }^{2}$ so that the right ventricle has to overcome both this congestion and the back flow which takes place during systole of the left ventricle. In the same manner enlargement of the right auricle causes pressure on the right pulmonary veins (Fig. 1\%), and it seems to us highly probable that it is this factor of pressure on the pulmonary veins ${ }^{3}$ which aids materially in producing pulmonary congestion and pleural leakage, as well as in promoting failure of competence of the right side of the heart.

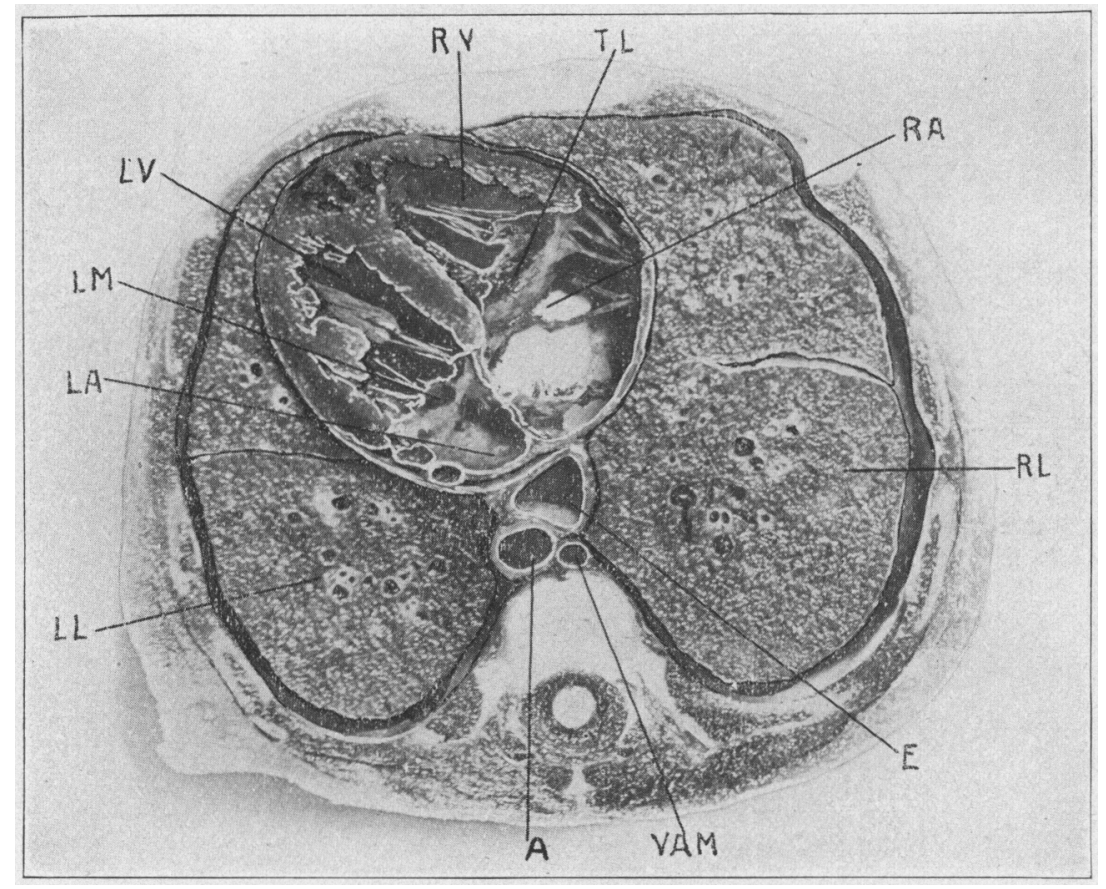

Fig. 7.-Horizontal section, viewed from above, of the body of a new-born child at the level of the upper border of the fifth rib. A, thoracic aorta; LL, left lung; LA, left auricle; LM, mitral leaflet; LV, left ventricle; RV, right ventricle; TL, tricuspid leaflet; RA, right auricle; RL, right lung; E, esophagus; VAM, vena azygos major.

The relatively loud sound of the closure of the pulmonary valve in children, as compared with that of the aortic, may be due in part to the fact that the upper lobe of the left lung does not cover the pulmonary artery (Fig. 16) as well as in adults and possibly to the presence of the thymus (Fig. 16), which would furnish a good conducting medium from

2. Miller, W. S.: Am. Jour. Anat., vii, 404, 405.

3. Fetterolf and Landis: Am. Jour. Med. Sc., November, 1909. 
valve to chest wall. More important, however, is the physiologic aifference in systemic tension between child and adult.

From a correct conception of the position of the heart in vivo we may draw conclusions as to the pathologic anatomy in case of enlargement. Increase in size to the left would be due mainly to enlargement of the left ventricle ( $\mathrm{Fig} . \mathrm{r}$ ) ; to the left and upward mainly to the left auricular appendix (Fig. 18) and to a slight extent the left auricle (Fig. 10); to the left and clownward to the left and right rentricles (Figs. 7 and 13). Enlargenent to the right would involve mainly the right auricle

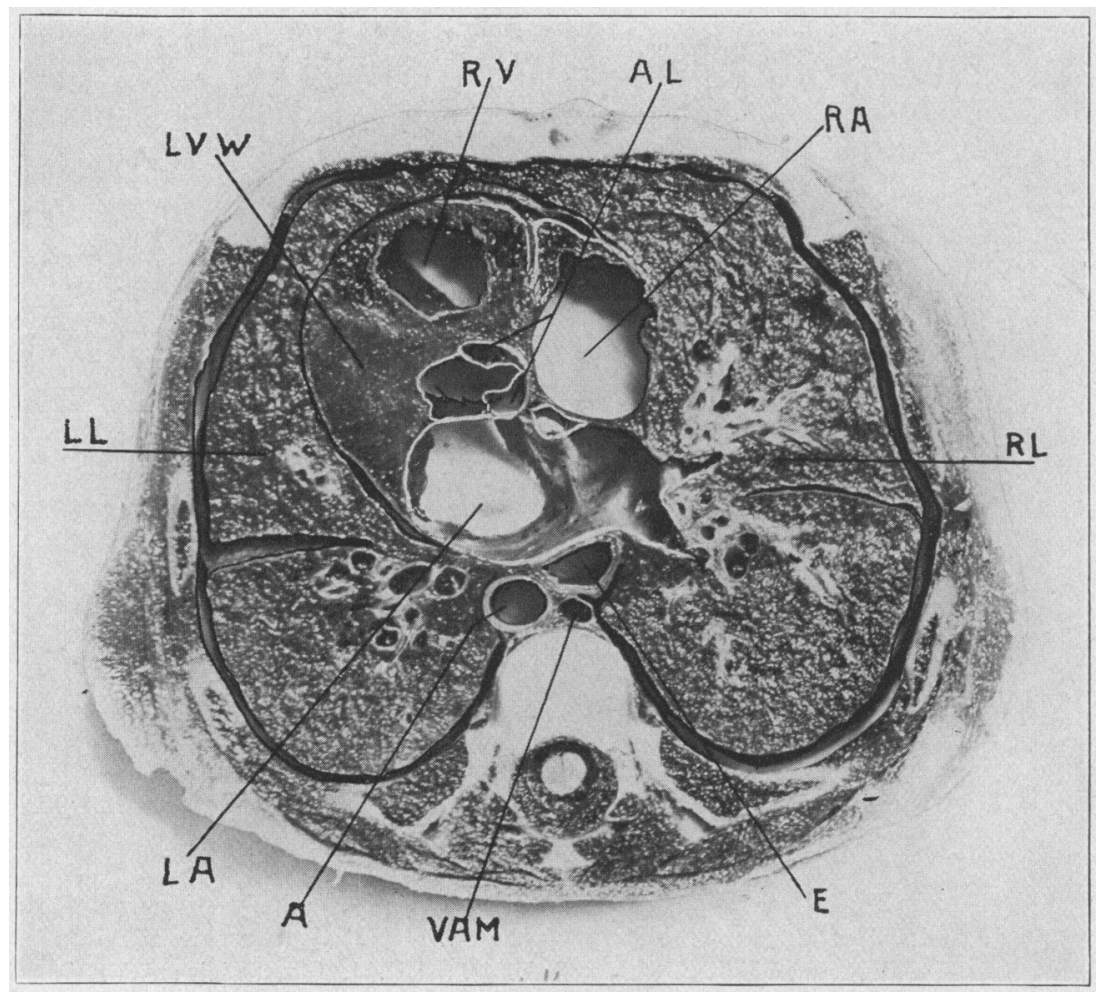

Fig. 8.- Horizontal section, viewel from above, of the body of a new-born child at the level of the upper border of the fourth rib. VAM, vena azygos major; A, aorta; JA, left auricle; LL, left Jung; LVIV, left ventricular wall; $\mathrm{RV}$, right ventricle; $\mathrm{AI}$, antic leaflet; $\mathrm{RA}$, right auricle; $\mathrm{RJ}$, right lung; $\mathrm{E}$, esophagus.

and appendix (Fig. 11), and to a lesser extent the right rentricle and the right end of the left auricle (Fig. 11).

A noteworthy point is that the mitral, trieuspid and nortic ralves are practically contiguons structures (Fig. 12). This readily explains the difficulty in distinguishing the murmurs produced in cases of double or 


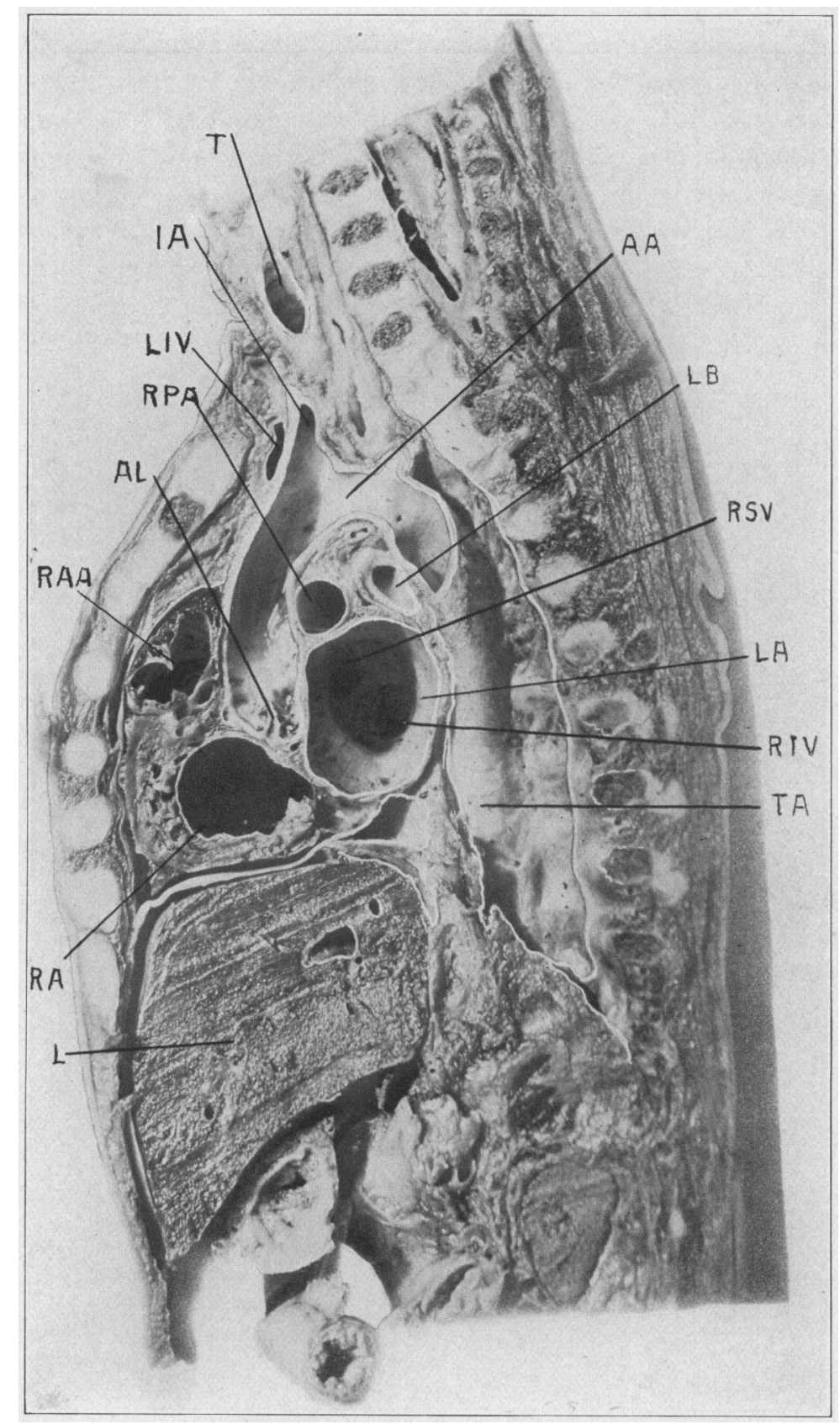

Fig. 9.-Sagittal section, viewer from the left, of the body of a new-born child, the plane of section being $0.75 \mathrm{~cm}$. to the left of the midsternal line. L, liver; RA, right auricle; RAA, right auricular appendix; AI, aortic leaflets; RPA, right pulnonary artery; LIV, left innominate rein: IA, innominate artery; T, trachea; $A A$, aortic arch: $\mathrm{IB}$, left bronchus; RSV, right superior pulmonary vein; JA, left auricle; RIV, right inferior pulmonary vein; TA, thoracic aorta. 
triple lesions or leakage. When we add to this the ease with which cardiac sounds, both normal and abnormal, can be heard in children, owing principally to the thinness of the chest wall, it would appear that a differentiation between a mitral and a tricuspid regurgitation, for example, would be impossible from the murmurs alone. A systolic murmur heard in the left axilla but not in the carotids or right axilla, would indicate mitral regurgitation. An aortic systolic murmur can be diagnosed with certainty only in the neck, while a systolic murmur heard over the heart, but not in the left axilla or in the neck, would point more strongly to a

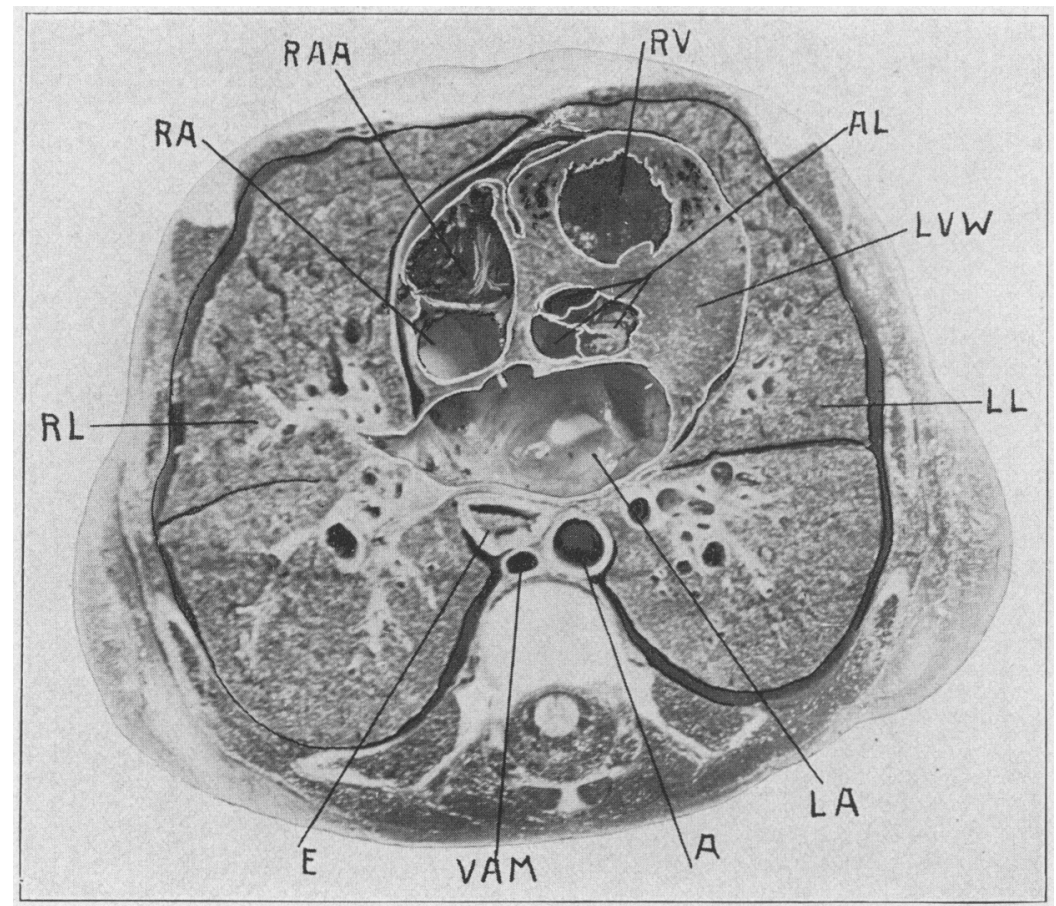

Fig. 10.-Horizontal section, viewed from below, of the body of a new-born child at the level of the upper border of the fourth rib. VAM, vena azygos major; E, esophagus; RL, right lung; RA, right auricle; RAA, right auricular appendix; RV, right ventricle; $A L$, aortic leaflets; $L V W$, left ventricular wall; LL, left lung; LA, left auricle; A, aorta.

functional cause than to tricuspid regurgitation. A pure diastolic murmur heard anywhere over the heart is usually due to aortic regurgitation.

Some interesting features in regard to the lungs have been noted. Everyone is familiar with the normal relative differences between the physical signs over the right and left apices. Various explanations have 


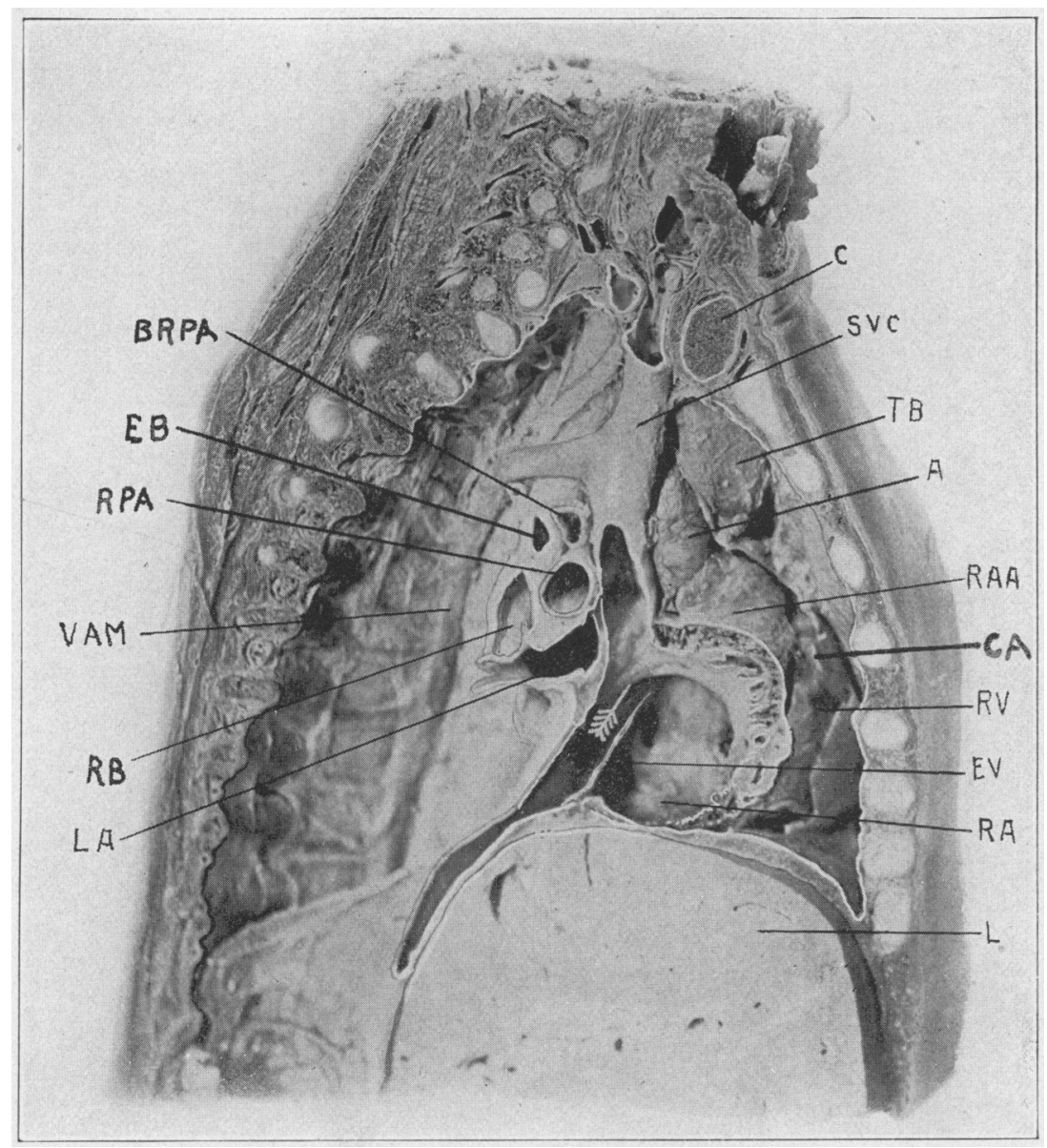

Fig. 11.--Sagittal section, viewed from the right, of the body of a new-born child, the plane of section being $0.75 \mathrm{~cm}$. to the right of the midsternal line. $\mathrm{LA}$, left auricle; RB, right bronehus; VAM, vena azygos major; RPA, right pulmonary artery; EB, eparterial bronchus; BRPA, branch of right pulmonary artery; C, clavicle; SVC, superior vena cava; 'TB, thymus body; A, root of aorta; RAA, right aurieular appendix; $C A$, conus arteriosus; $R V$, right ventricle; EV, Eustachian valve; RA, right auricle; L, liver. The arrow is in the foramen ovale. 


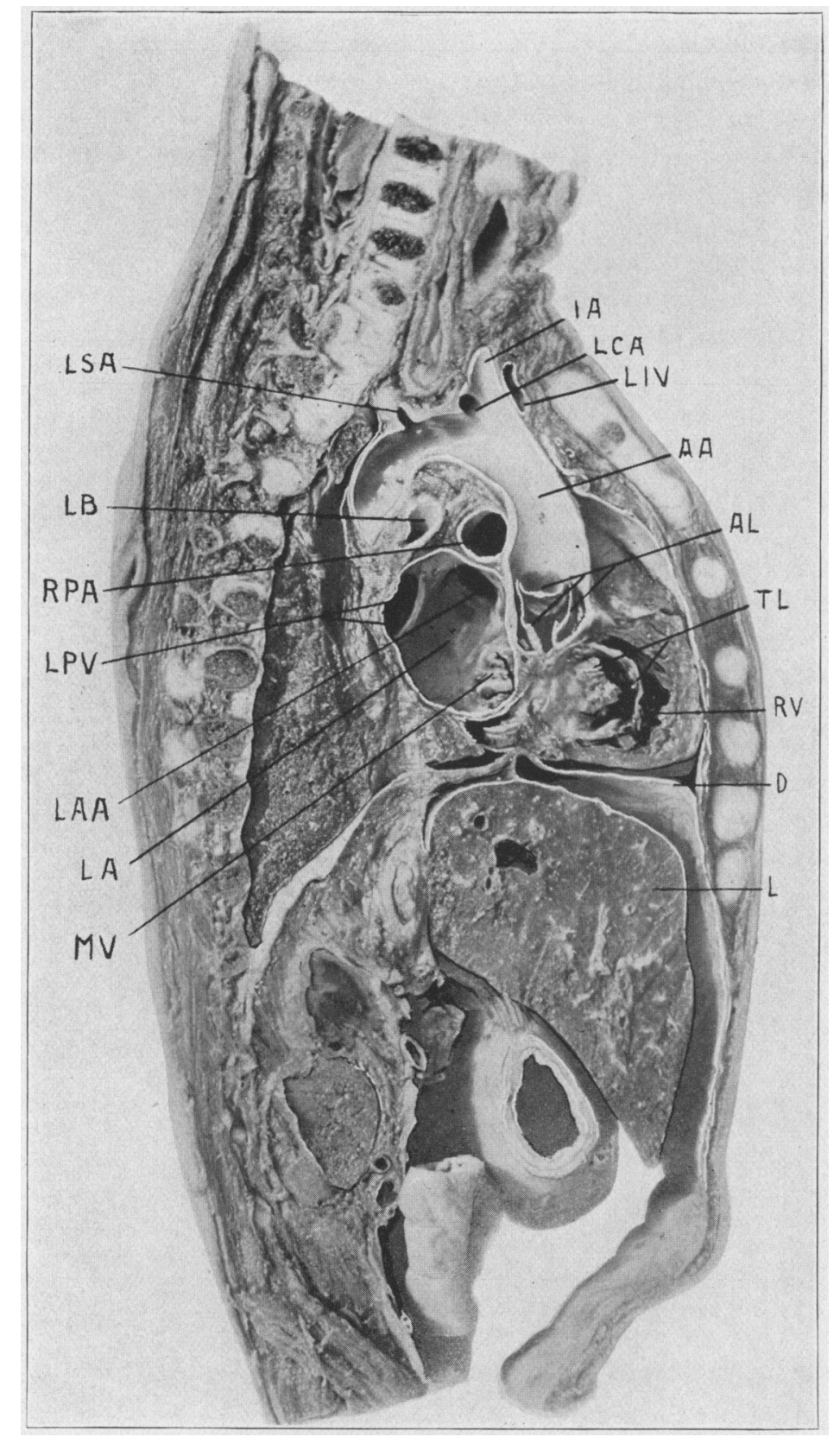

Fig. 12.-Sagittal section, viewed from the right, of the body of a new-born child, the plane of section being $0.75 \mathrm{~cm}$. to the left of the midsternal line. MV, mitral valve; IAA, left auricle; LAA, left auricular appendix; LPV, orifices of left pulmonary veins; RPA, right pulmonary artery; LB, left bronchus; LSA, left subclavian artery; IA, innominate artery; LCA, left common carotid artery; LIV, left innominate vein; AA, aortic arch; AL, aortic leaflets; TI, tricuspid leaflets; $R V$, right ventricle: $D$, diaphragm; $I$, liver. 
been offered from time to time but the one pointed out by one of us ${ }^{4}$ is shown clearly in our preparations. This explanation rests on the anatomic relations of the trachea and the pulmonary apices. On the right side they are absolutely contiguous structures (Fig. 2 ), while on the left they are separated by the aorta, the left carotid and subclavian arteries, the esophagus and some areolar and I ymphoid tissue (Fig. 2). In this connection should be mentioned the dulness to the left of the upper sternum to which attention has been called by Hamill and LeBontilline." "This is probably due partly to the facts just mentioned, partly to the exposure of

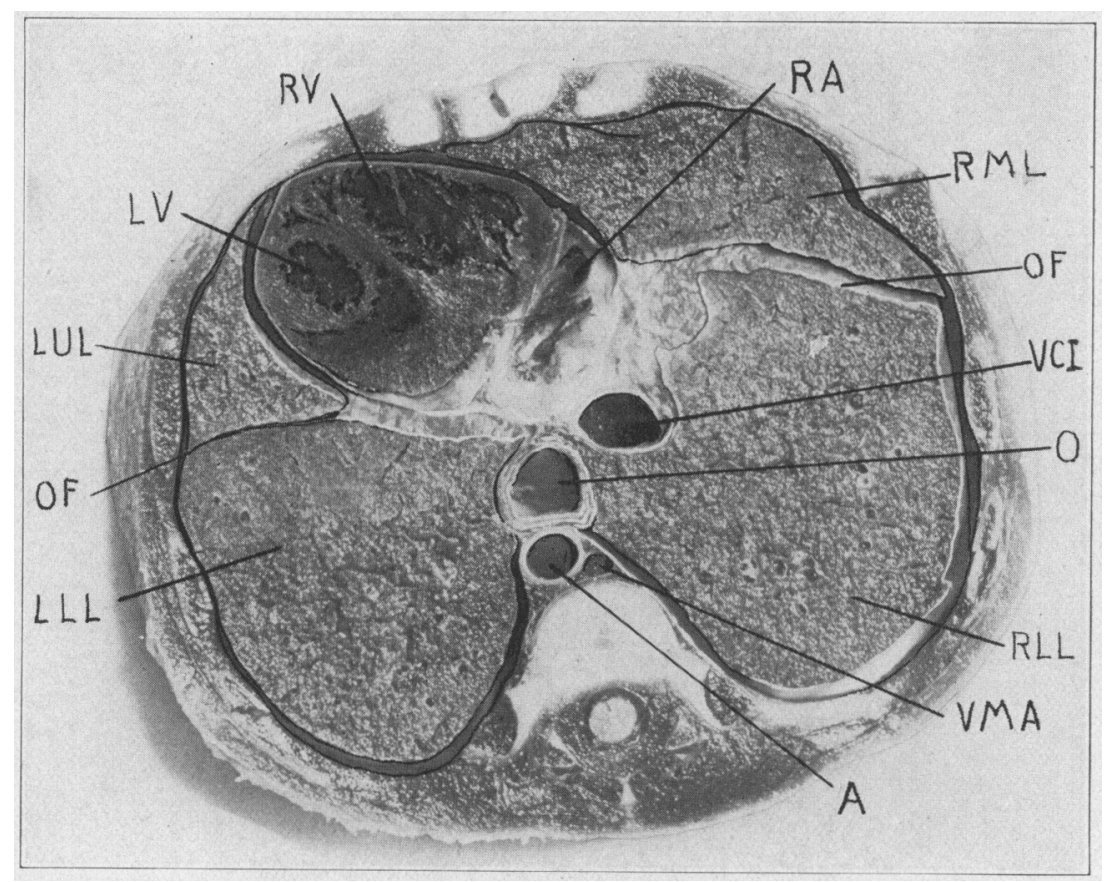

Fig. 13.-Horizontal section, viewed from above, of the body of a new-born child at the level of the upper portion of the ensiform cartilage. LLL, lower lobe of left lung; $O F$, oblique fissure of left and right lungs: LUL, upper lobe of left lung; $L V$, left ventricle; $R V$, right ventricle; $R A$, right auricle; $R M L$, middle lobe of right lung; VCT, vena eava inferior; $O$, esoplagnus; RT., lower lobe of right lung: VMA, vena aygos major: $A$, aorta.

the pulmonary artery on account of the posterior position of the anterior margin of the left lung as compared with the adult. and partly to the

4. Fetterolf, George: The Anatomic Explanation of the Greater Amount of Vocal Fremitus and Vocal Resonance Normally Found at the Apex of the Right Lung, Arch. Int. Med., February, 1909, p. 23.

5. IIamill, Samuel MeC., and LeBoutillier. Theodore: Some Physical Signs in Infants and Children Not Sufficiently Emphasized, Jour. Am. Med. Assn., Jan. 7,1905 , p. 26. 


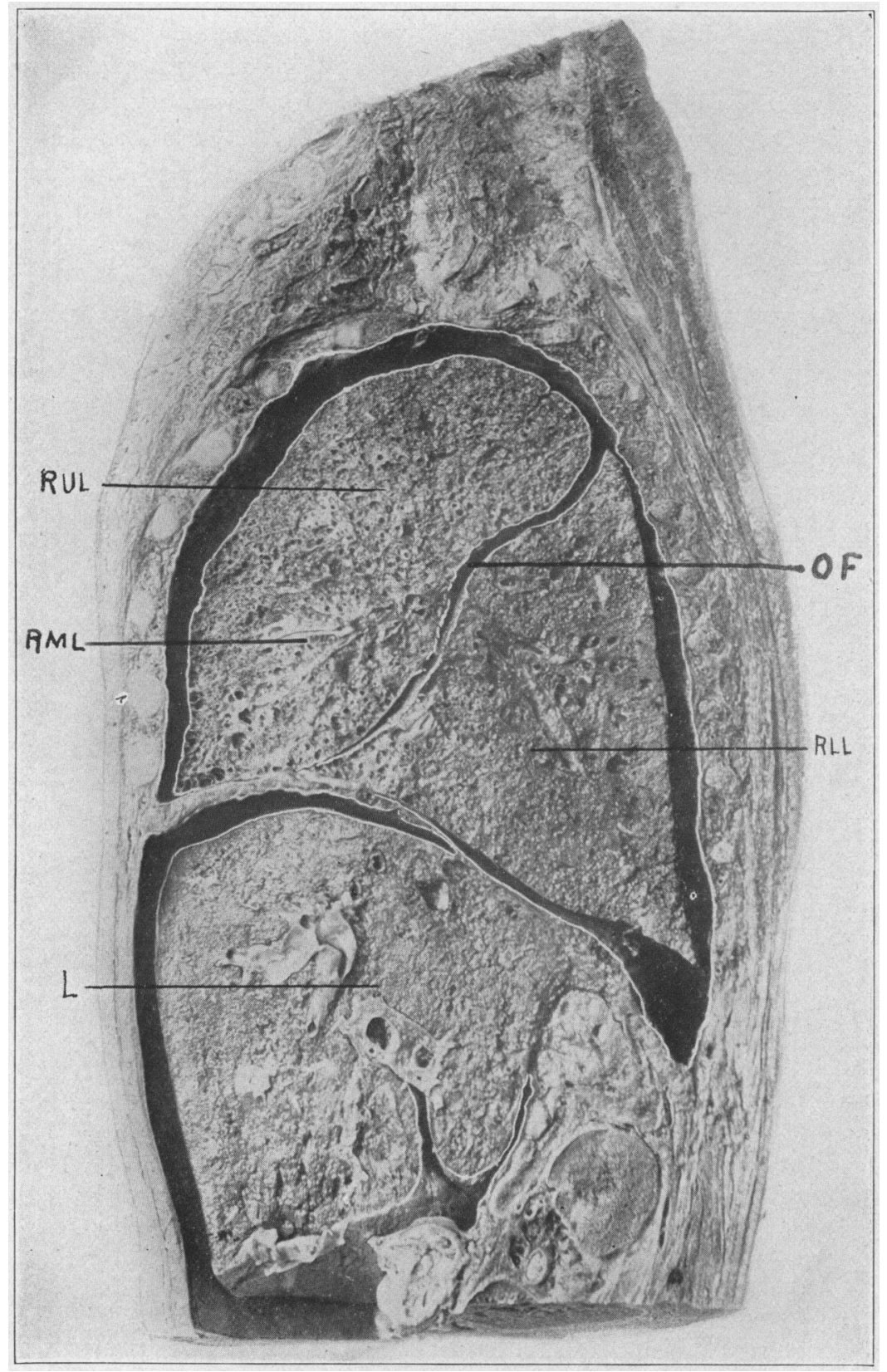

Fig. 14.- Sagittal section, viewed from the left, of the body of a new-born child, the plane of section being $2 \mathrm{~cm}$. to the right of the midsternal line. Owing to adhesions the horizontal fissure is not shown. L, liver; RML, middle lobe of right lung; RUI, upper lobe of right lung; OF, oblique fissure; RLL, lower lobe of right lung. 


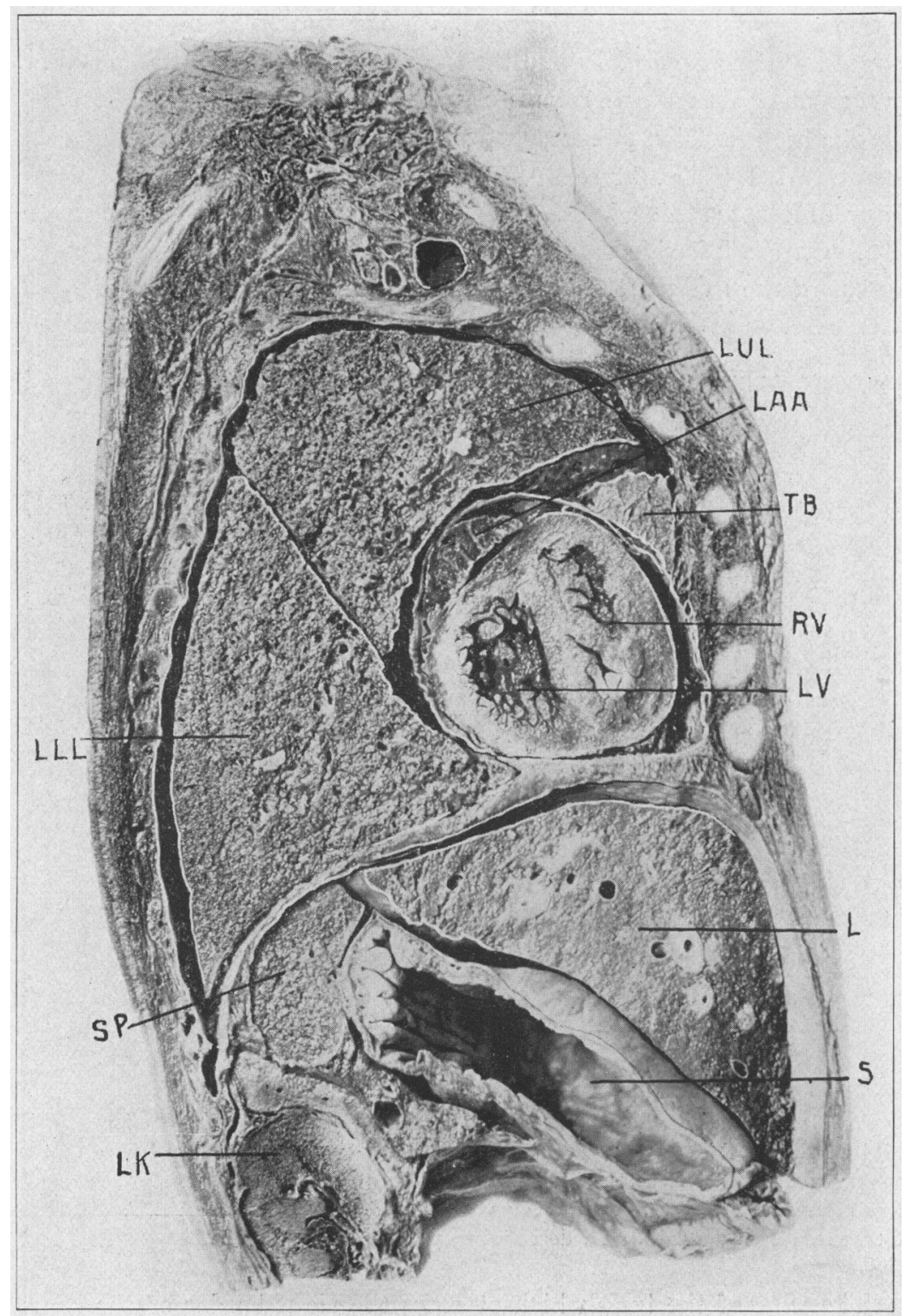

Fig. 15.- Sagittal section, viewed from the right, of the body of a new-born child, the plane of section being $2 \mathrm{~cm}$. to the left of the midsternal line. LK, left kidney; SP, spleen; LLI, lower lobe of left lung; LLI, upper lobe of left lung; LAA, left auricular appendix; TR, thymus body: RV, right ventricle; $L V$, left ventricle; $\mathrm{L}$, liver; $\mathrm{S}$, stomach. 
greater extent of the left lobe of the thymus (Fig. 1). In addition, the left lobe of the thymus is backed by a mass of solid tissue interposed between the left upper lobe and the trachea, while the rignt lobe is backed by resonating tissue in the shape of the right upper pulmonary lobe.

The high position of the dome of the liver on the right side is clearly demonstrated (Figs. 11 and 14) and explains the high-pitched or relatively dull note which is heard in pereussing over the right pulmonary base. On the left side the spleen is seen to reach a level almost as high as that of the liver, the difference being not more than that of a rib and interspace.

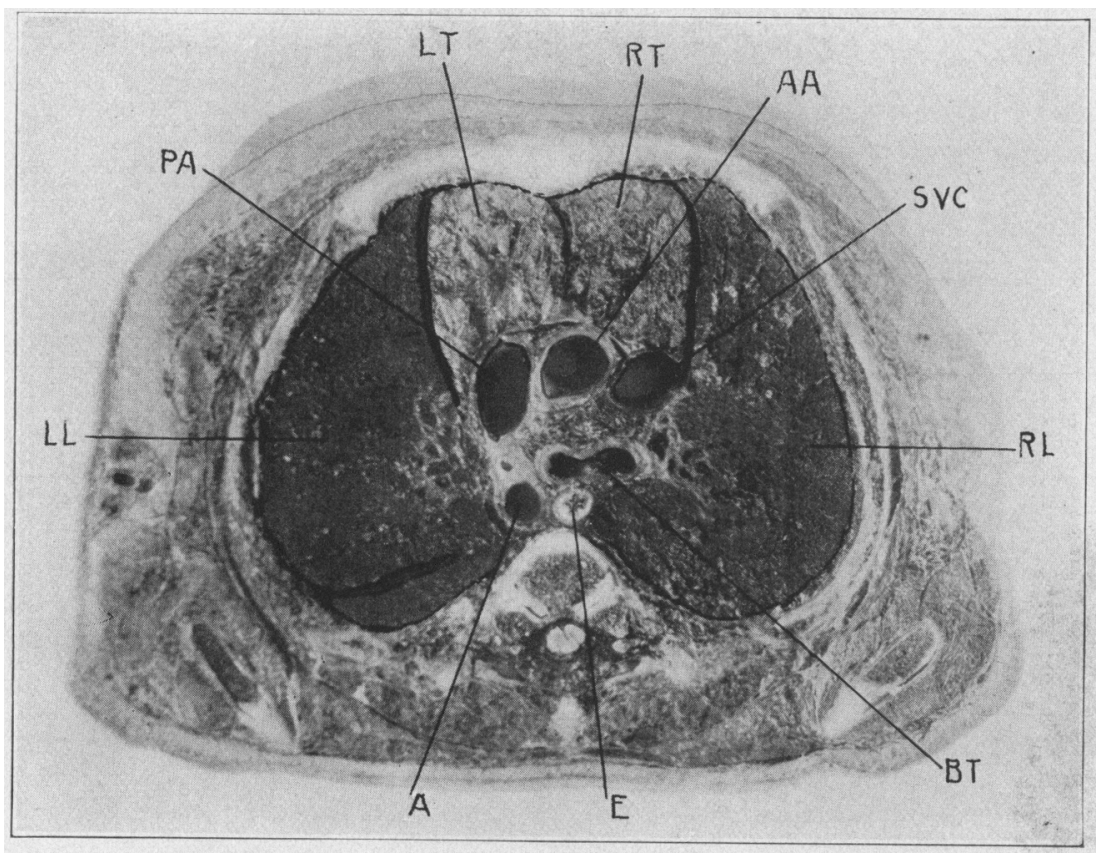

Fig. 16.-Horizontal section, viewed from above, of the body of a new-born child at the level of the upper border of the third rib. LL, left lung; PA, pulmonary aorta; L', left lobe and R'I, right lobe of thymus body; AA, ascending part of aortic arch; SVC, superior vena cava; RL, right lung; BT, bifurcation of trachea; $E$, esophagus; $A$, descending part of aortic arch.

The edge of the lung which overlaps the right border of the heart is so thin (Fig. 10) that it should hardly interfere with a reasonably accurate determination of the right border of cardiac dulness.

The position of the bronchial lymph nodes at the bifurcation of the trachea (Fig. 16) is so far above the heart, which would furnish a conducting medium, that it is difficult to conceive how enlargement of these nodes could produce a bruit, even on forced extension of the head, which 


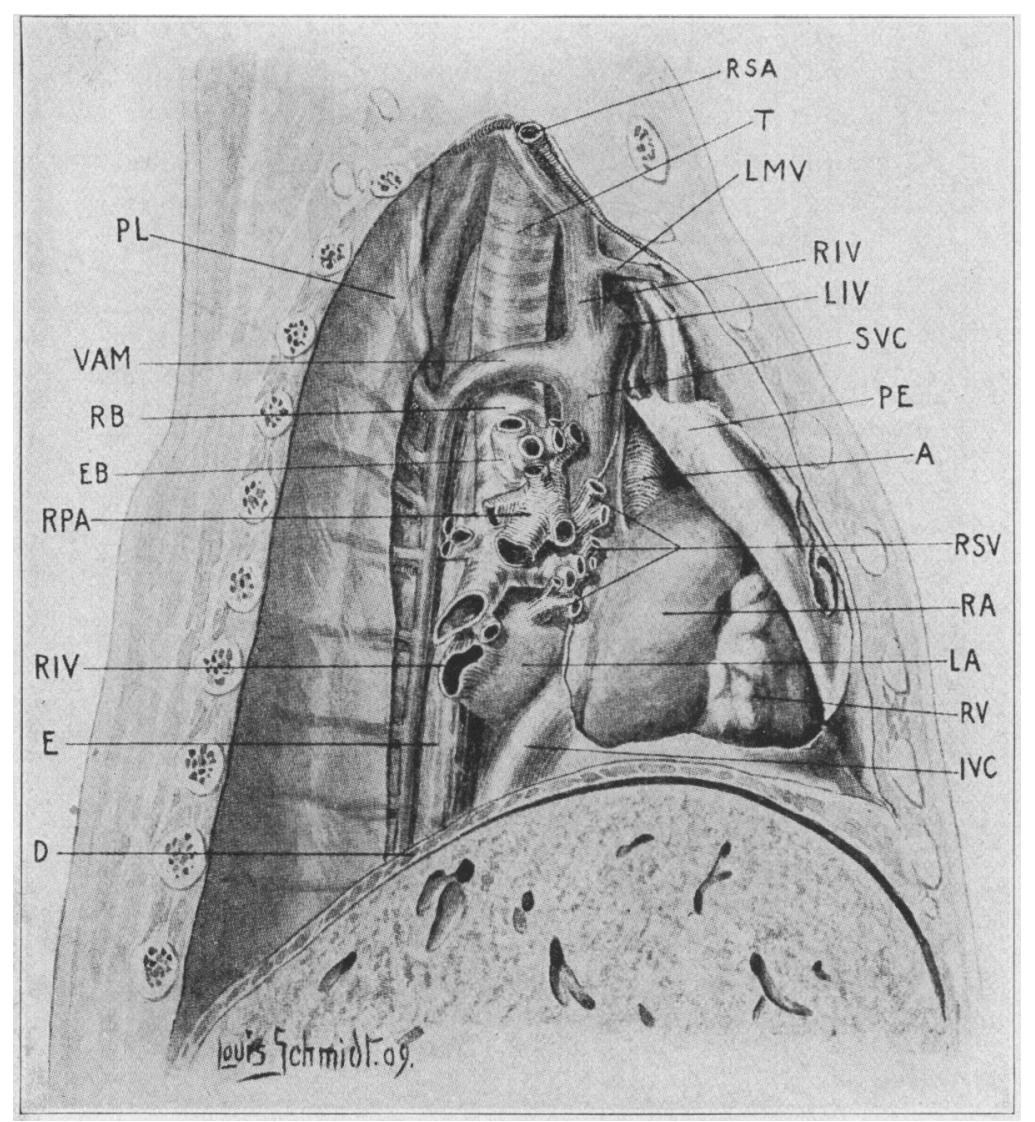

Fig. 17.-View from the right of the mediastinal contents and the root of the lung of the body of a 6-months-old child. D, diaphragm; E, esophagus; RIV, right inferior pulmonary vein; RPA, riglt pulmonary artery; EB, eparterial bronchus; RB, right bronchus; VAM, vena azygos major; PL, pleura; RSA, right subclavian artery; 'T, trachea; LMV, right internal mammary vein; RIV, right innominate vein; LIV, left innominate vein; SVC, superior vena cava; $\mathrm{PE}$, pericardium; A, aorta; RSV, right superior pulmonary vein; RA, right auricle; $L A$, left auricle; $R V$, right ventricle; IVC, inferior vena cava. (Fetterolf and Landis: Am. Jour. Med. Sc., November, 1909.) 


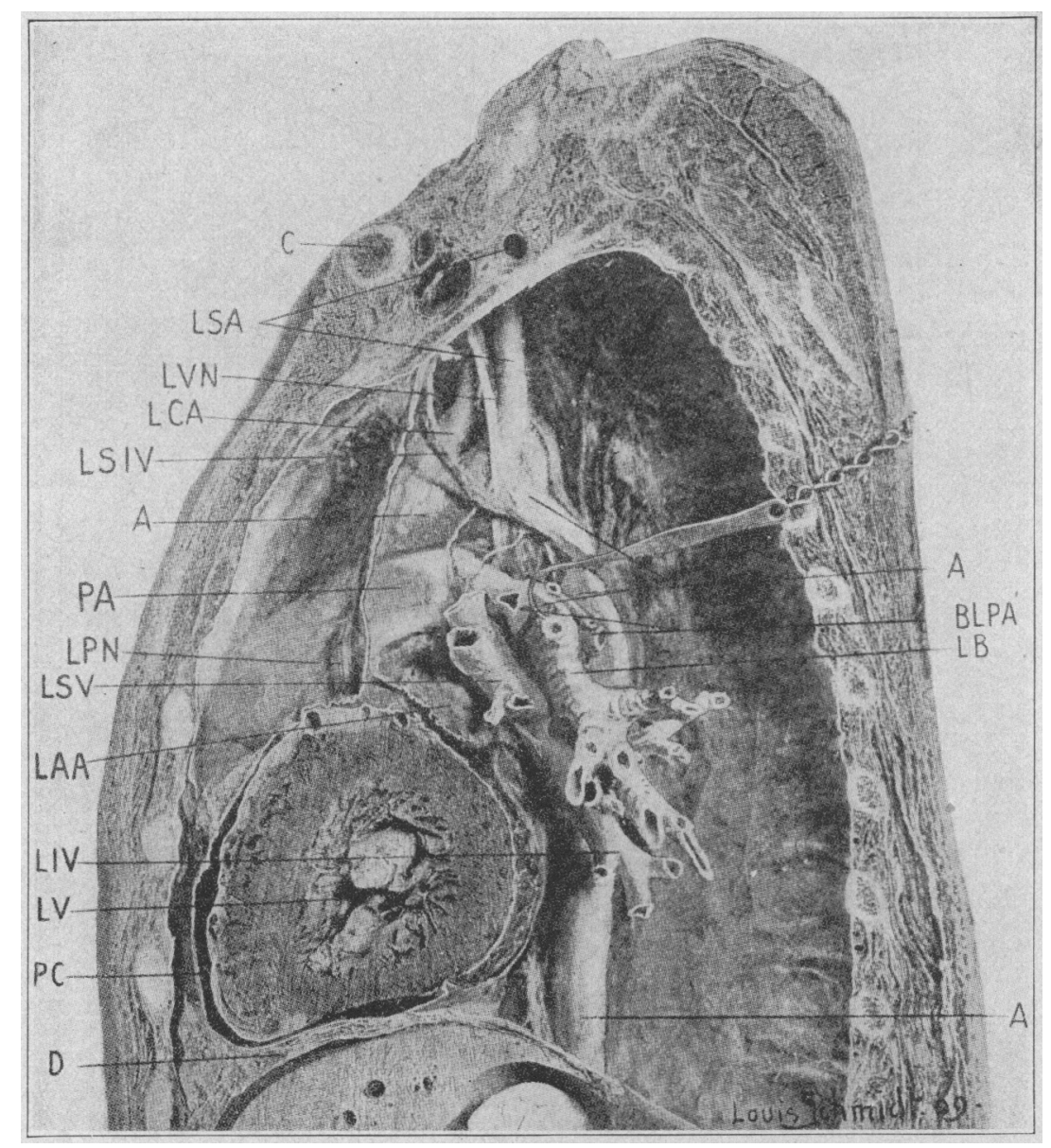

Fig. 18.-View from the left of the mediastinal contents and root of the left lung of the body of an adult. J), diaphragm; $\mathrm{PC}$, pericardial chamber; LV, left ventricle; LIV, left inferior pulmonary vein; LAA, left auricular appendix; LSV, left superior pulmonary vein; LPN, left phrenic nerve; PA, pulmonary aorta; A, aorta; LSIV, left superior intercostal vein; LCA, left common carotid artery; LVN, left vagus nerve; LSA, Jeft subclavian artery; C, elavicle; $A$, A, A, aorta; BLPA, branch of left pulmonary artery; LB, left bronchus. (Fetterolf and Landis: Am. Jour. Mcd. Sc., November, 1909.) This section, while that of an adult, shows the points under discussion so well that it is used in preference to preparing a new dissection of an infant. 
could be heard over the upper sternum. The explanation of this bruit would seem to depend rather on the persistence of the thymus, which could exert pressure on the vessels as they arise from the arch of the aorta (Fig. 3).

Since the bronchial nodes are surrounded by so many other structures which would give a dull note on pereussion, such as the arch of the aorta, the great vessels, and the thymus, it seems to us highly problematical that enlargement of these nodes can be accurately diagnosed by percussion.

Finally, the sections afford a clear demonstration of the position of the lobes of the lungs and emphasize the fact that physical signs in the lungs posteriorly, as high as the base of the spines of the scapulæ, are produced in the lower lobes (Figs. 14 and 15). Anteriorly, on the right, the fourth rib divides the upper from the middle lobe, while on the left any signs heard above the heart and in front of the anterior axillary line would denote that the upper lobe is affected.

330 South Sixteenth Street-3942 Chestnut Street. 